\title{
The effect of lanthanum addition on the catalytic activity of $\gamma$-alumina supported bimetallic Co-Mo carbides for dry methane reforming
}

\author{
Liam J. France $\cdot$ Xian Du • Naif Almuqati $\cdot$ Vladimir L. Kuznetsov $\cdot$ \\ Yongxiang Zhao $\cdot$ Jiang Zheng • Tiancun Xiao • Abdulaziz Bagabas • \\ Hamid Almegren • Peter P. Edwards
}

Received: 6 March 2014/Accepted: 31 March 2014/Published online: 27 April 2014

(c) The Author(s) 2014. This article is published with open access at Springerlink.com

\begin{abstract}
The effect of lanthanum addition to $\gamma$-alumina supported bimetallic carbides has been studied for the reaction of dry methane reforming using four different lanthanum loading levels of 1, 5, 10 and $15 \mathrm{wt} \%$ of lanthanum. It has been demonstrated that the addition of lanthanum to supported bimetallic carbides at low loading levels $(1 \mathrm{wt} \%)$ results in smaller carbide crystallite sizes compared to catalysts containing either no lanthanum or higher lanthanum loading levels (5-15 wt\%). Increased lanthanum loading results in increased carbon dioxide desorption at $500-700{ }^{\circ} \mathrm{C}$. Reactions indicated that increased lanthanum loading resulted in significantly reduced product yields due to increased reverse water-gas shift activity. All materials exhibited degrees of sintering during the reaction. It was found that cobalt reacted with lanthanum species to form a $\mathrm{LaCoO}_{3}$ phase. The $1 \mathrm{wt} \%$ catalyst possessed superior catalytic properties for dry methane reforming and was tested for $100 \mathrm{~h}$. After an initial loss of activity, the catalyst appeared to stabilise, however, a decrease of $\sim 3 \%$ in the $\mathrm{H}_{2}$ : $\mathrm{CO}$ ratio, evidence
\end{abstract}

L. J. France $\cdot$ X. Du · N. Almuqati · V. L. Kuznetsov

J. Zheng $\cdot$ T. Xiao $\cdot$ P. P. Edwards $(\varangle)$

Department of Chemistry, University of Oxford, South Parks Rd,

Oxford OX1 3QR, UK

e-mail: Peter.Edwards@chem.ox.ac.uk

L. J. France

e-mail: liam.france@chem.ox.ac.uk

Y. Zhao

School of Chemistry and Chemical Engineering, Shanxi

University, Taiyuan 030006, China

A. Bagabas · H. Almegren

Petrochemical Research Institute, King Abdulaziz City of

Science and Technology (KASCT), King Abdullah Rd, Riyadh

11442, Saudi Arabia of carbide crystallite growth and carbon deposition, indicated that a shift in the side reactions had occurred during the reaction.

Keywords Dry methane reforming - Bimetallic carbide · Lanthanum - Carbon dioxide

\section{Introduction}

Due to our current reliance on petrochemical feed stocks, carbon dioxide emissions will continue to soar while we are employing combustion-based processes. From the environmental perspective, the application of carbon capture and storage technologies would effectively negate carbon dioxide emissions, resulting in a stabilisation of manmade contributions. Although such technologies are more than viable for stationary sources of carbon dioxide emissions, there are still no viable routes for incorporation into vehicles equipped with combustion engines. However, storage of carbon dioxide is a waste of a free carbon-based resource, when it may be converted into fuels or their precursors. This could help to provide a solution to two major current issues; global warming and the imminent energy crisis.

One potential route that is currently being examined by the start-up company $\mathrm{NewCO}_{2}$ Fuel is the application of dry methane reforming (DMR) employing renewable energy sources for generating synthesis gas (syngas) [28]. Prior to this, DMR has only found limited industrial application. Most notably in the form of the SPARG and CALCOR processes [11]. The SPARG process combines methane combustion (MC), partial oxidation of methane (POM), steam reforming (SR) and DMR. By implementing such a process, MC not only yields the oxygenated feed streams 
used in both SR and DMR, but also supplies energy to the endothermic reactions resulting in lower external energy requirements. POM, SR and DMR produce syngas as the product [32]. However, commercially in SR, carbon monoxide is further reacted in the presence of water to yield hydrogen and carbon dioxide via the water gas shift reaction (WGS). SR and DMR are described by Eqs. 1 and 2, respectively.

\section{Steam reforming}

$\mathrm{H}_{2} \mathrm{O}+\mathrm{CH}_{4} \rightarrow 3 \mathrm{H}_{2}+\mathrm{CO}+206 \mathrm{~kJ} \mathrm{~mol}^{-1}$

Dry methane reforming

$\mathrm{CO}_{2}+\mathrm{CH}_{4} \rightarrow 2 \mathrm{H}_{2}+2 \mathrm{CO}+247 \mathrm{~kJ} \mathrm{~mol}^{-1}$

Both of these reforming processes are highly endothermic requiring significant external energy input to proceed. While they are similar in the respect that they are both endothermic, they could not be more different chemically. SR utilises water, which results in significant hydrogen yield giving a syngas ratio of 3:1. DMR utilises carbon dioxide, which results in a more endothermic process, however, it reforms two major greenhouse gases and yields (theoretically) a 1:1 syngas composition, which is known to be particularly useful for the synthesis of hydrocarbons [18].

Subsequently, much research has been conducted on the DMR process, in particular with cobalt and nickel, which are well known for their significant $\mathrm{C}-\mathrm{H}$ bond activation ability [4]. While this is a mature reaction, many "new" classes of catalysts have been investigated in recent years to examine their performance in this promising area. In particular, group VI carbides have shown a particular affinity towards such processes [2]. This has been attributed to the hybridised electron configuration of the metal, which resembles that of the noble metals and has been shown previously to possess some properties similar to those exhibited by platinum [22].

In particular, monometallic molybdenum carbide, $\mathrm{Mo}_{2} \mathrm{C}$, has been tested as a catalyst for a number of reactions, including SMR [7], DMR [8, 9, 21, 26], POM [36] and hydrotreating [37]. The use of supported metal carbides was also considered in an attempt to further improve catalytic activity and stability of these materials. Studies undertaken by Brungs et al. [2] examined the use of a number of supports $\left(\mathrm{Al}_{2} \mathrm{O}_{3}, \mathrm{SiO}_{2}, \mathrm{TiO}_{2}\right.$ and $\left.\mathrm{ZrO}_{2}\right)$ for molybdenum carbide $\left(\mathrm{Mo}_{2} \mathrm{C}\right)$ catalysts. The authors were able to determine a stability order for the supported materials which showed that alumina supported monometallic carbides exhibited the highest catalytic stability in DMR.

It has also been reported that the addition of a second metal, e.g. Co, has a significant effect on the catalytic activity of Mo carbides [1, 37]. Xiao et al. produced a series of CoMo bimetallic carbides with different Co:Mo ratios. It was observed that at low Co:Mo ratios, a homogeneous bimetallic carbide phase was formed. However, materials with higher Co:Mo ratios, e.g. $\mathrm{Co}_{0.4} \mathrm{Mo}_{0.6} \mathrm{C}_{x}$ and $\mathrm{Co}_{0.5} \mathrm{Mo}_{0.5} \mathrm{C}_{x}$, exhibited a number of impurity phases, primarily $\mathrm{Co}$ and $\mathrm{Mo}_{2} \mathrm{C}[6,37]$. A small number of studies have been conducted on the use of supported bimetallic carbide systems for DMR, employing a rather diverse number of supports such as $\gamma$-alumina $[6,10,19,30]$, activated carbon [23, 27], MCM-41 [35] and SBA-15 [14].

Additive studies were reported by Darujati et al. specifically the use of ceria was explored as an additive to $\gamma$ alumina supported $\mathrm{Mo}_{2} \mathrm{C}$. It was found that although no obvious change in activation energy was observed for $\mathrm{Mo}_{2} \mathrm{C}$ as a bulk or supported catalyst, the ceria-promoted material exhibited a higher activity, which was attributed to improved dispersion of the catalyst due to the support. However, ceria was found to act as an active site for strong $\mathrm{CO}_{2}$ adsorption, which lowered the reaction order of $\mathrm{CO}_{2}$ to zero. A redox cycle was also proposed which accounted for $\mathrm{CO}_{2}$ and $\mathrm{CO}$ interactions with the $\mathrm{Ce}^{3+}$ and $\mathrm{Ce}^{4+}$ oxides [9]. It was determined that ceria had to be impregnated into the support and calcined prior to molybdenum impregnation. Additionally, Darujati et al. examined additives such as $\mathrm{K}$ and $\mathrm{Zr}$. It was found that $\mathrm{K}$ significantly decreased surface molybdenum concentrations resulting in reduced activity and rapid deactivation. $\mathrm{Zr}$ was found to have no obvious effect on either methane conversion or deactivation rates [8].

Lanthanum-like cerium and their oxides are well known as catalyst additives and their use is well documented. In zeolitic materials, both are known to possess similar properties in that they enhance acid site density in conjunction with mediating carbon lay down during fluidised catalytic cracking [29] and [20]. Additionally, their application as a phase stabiliser for transitional support materials such as titania and alumina has been documented [12, 13]. It has been reported previously that simple perovskites of the type $\mathrm{LaMO}_{3}(\mathrm{M}=\mathrm{Ni} / \mathrm{Co} / \mathrm{Fe})$ have been reduced and then used as a catalyst in the DMR reaction. It was found that lanthanum oxide adsorbed carbon dioxide, which readily converted carbon generated by methane cracking (MCr) into carbon monoxide [33]. While the use of ceria as an additive for supported molybdenum carbide has been reported previously the use of the more abundant lanthanum and its oxides has not to the best of our knowledge been investigated previously on either monometallic or bimetallic carbides.

The present work examines the effect of La addition to $\gamma$-alumina supported bimetallic carbides in DMR, with particular emphasis on the stability of the catalysts during 
reactions in the presence of excess carbon dioxide at high reaction temperatures. Analysis of the catalysts prior to reaction was undertaken to understand the effects that the presence of La may have had on the formation of the carbide. Additionally, analysis of post-reaction catalysts were conducted to examine changes of the active phase during reaction and to assess the stability of the carbides in the presence of lanthanum during dry methane reforming.

\section{Experimental}

\section{Catalyst preparation}

$\gamma$-alumina high surface area catalyst support (Alfa Aesar, $250 \mathrm{~m}^{2} \mathrm{~g}^{-1}$ ) was ground and sieved to a particle size of $125-250 \mu \mathrm{m}$. Six different supports were generated in $5 \mathrm{~g}$ batches, these contained $0,1,5,10$ and $15 \mathrm{wt} \% \mathrm{La}$. These were produced by adding together lanthanum (III) nitrate hexahydrate (Sigma-Aldrich, Fluka $\geq 99.0 \%$ ) and citric acid (Alfa Aesar, Anhydrous ACS, 99.5 + \%) in a 1.0:1.5 molar ratio, respectively. The resultant mixture was added in a required proportion to sieved alumina and mixed with manual grinding for 30 min prior to adding water and mixing to a stiff paste. For the purpose of comparison, the $0 \mathrm{wt} \%$ La sample also underwent mixing and adding of water. The supports were dried at $110{ }^{\circ} \mathrm{C}$ for $3 \mathrm{~h}$ and then heated in air at $10{ }^{\circ} \mathrm{C} \mathrm{min}^{-1}$ to $850{ }^{\circ} \mathrm{C}$ and kept at this temperature for $3 \mathrm{~h}$. Once cooled, the supports were ground and sieved to a particle size of $125-250 \mu \mathrm{m}$.

$3 \mathrm{~g}$ of each support was added to $50 \mathrm{ml}$ of a solution containing ammonium heptamolybdate tetrahydrate (Sigma-Aldrich, ACS, $\geq 99.99 \%$ ) cobalt (II) nitrate hexahydrate (Sigma-Aldrich, ACS, $\geq 98 \%$ ), nitric acid (SigmaAldrich, $70 \%$ ) and an excess of citric acid (Alfa Aesar, Anhydrous ACS, $99.5+\%$ ) and distilled water. The mixture was stirred vigorously for $24 \mathrm{~h}$ and then heated at $120{ }^{\circ} \mathrm{C}$ for $2 \mathrm{~h}$ to remove excess water. The resultant solids were transferred to alumina crucibles, heated at $5{ }^{\circ} \mathrm{C} \min ^{-1}$ to $600{ }^{\circ} \mathrm{C}$ and kept at this temperature for $10 \mathrm{~h}$. Once cooled, the precursor solids were removed and sieved to $<250 \mu \mathrm{m}$. The target loading level of the oxide precursor was $40 \mathrm{wt} \%$ ( $\sim 30 \mathrm{wt} \%$ carbide) in all instances with a Co:Mo molar ratio of 0.67 .

The precursors $(\sim 2.5 \mathrm{~g})$ were then reduced and carburised under a continuous flow of methane (BOC, $99.9 \%$ ) and hydrogen (BOC, $99.9 \%$ ) with a ratio of 20:80 volume

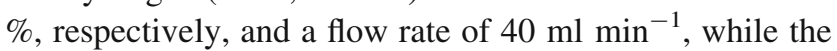
temperature was increased at $3{ }^{\circ} \mathrm{C} \mathrm{min}-1$ to $750{ }^{\circ} \mathrm{C}$ and held for $3 \mathrm{~h}$. The samples were then allowed to cool to room temperature at $3{ }^{\circ} \mathrm{C} \mathrm{min}{ }^{-1}$ under argon (BOC $99.9 \%$ ). All catalysts were left in the quartz tube at room temperature for $24 \mathrm{~h}$ exposed to air prior to removal, subsequent characterisation and catalytic tests.

\section{Catalytic tests}

Catalytic reactions were undertaken in a stainless steel fixed bed plug flow micro reactor (Fig. 1) at atmospheric pressure. To reduce dead volume attributed to the reactor tube, carborundum (Fisher, General purpose grade, 24 mesh) was loaded above and below the catalyst bed separated with quartz wool wads (Fisher) to prevent the mixing of catalyst $(0.5000 \pm 0.0005 \mathrm{~g})$ with the carborundum. The catalyst was heated at $5{ }^{\circ} \mathrm{C} \mathrm{min}{ }^{-1}$ to $850{ }^{\circ} \mathrm{C}$ under $40 \mathrm{ml} \mathrm{min}^{-1}$ flow of dry nitrogen (BOC $99.999 \%$ ). Once the temperature had stabilised at $850{ }^{\circ} \mathrm{C}$, the gas supply was switched to a mixture (Air products special gas mixture, $99.99 \%$ ) containing methane, carbon dioxide and nitrogen $(33,39$

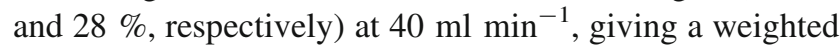
GHSV of $4,800 \mathrm{ml} \mathrm{hr}^{-1} \mathrm{~g}^{-1}$. Reactions were performed initially for $5 \mathrm{~h}$ to establish the most active catalyst, which was then tested for $100 \mathrm{~h}$. Gas analysis was undertaken every $30 \mathrm{~min}$ for the former reactions and every hour for the latter. The composition of the reactor effluent was monitored for $\mathrm{CH}_{4}, \mathrm{CO}_{2}, \mathrm{~N}_{2}, \mathrm{H}_{2}$ and $\mathrm{CO}$ using a Shimadzu GC 2014 Gas Chromatograph equipped with TCD and FID detectors employing a column-switching technique between a $1 \mathrm{~m}$ mole sieve $13 \times 60-80$ mesh packed column and a 3 m Hayesep N 60-80 mesh packed column; argon (BOC $99.999 \%)$ was used as the carrier gas. Post-reaction, the spent catalyst was cooled to room temperature under $40 \mathrm{ml} \mathrm{min}{ }^{-1}$ of dry nitrogen (BOC, $99.999 \%$ ) overnight and then exposed to air prior to unloading.

Conversion of component $x$ was defined as:

$1-\left(\frac{\left[X_{\text {oulet }}\right] \times\left[\mathrm{IS}_{\text {inlet }}\right]}{\left[X_{\text {inlet }}\right] \times\left[\mathrm{IS}_{\text {outlet }}\right]}\right) \times 100$

where $X$ is the concentration of either $\mathrm{CH}_{4}$ or $\mathrm{CO}_{2}$ in the feed, IS is the concentration of the internal standard $\left(\mathrm{N}_{2}\right)$.

The hydrogen and carbon monoxide yields were defined as:

$\frac{\mathrm{H}_{2 \text { outlet }}}{2 \mathrm{CH}_{4 \text { inlet }}}$

and

$\frac{\mathrm{CO}_{\text {outlet }}}{2 \mathrm{CO}_{2 \text { inlet }}}$

The product ratio was defined as:

$\underline{\mathrm{H}_{2} \text { outlet }}$

where all yields and the product ratio were calculated from $\mathrm{N}_{2}$ corrected flow rates at STP $\left(\mathrm{ml} \mathrm{min}{ }^{-1}\right)$. 
Fig. 1 A schematic representation of the dry methane reforming fixed bed plug flow reactor

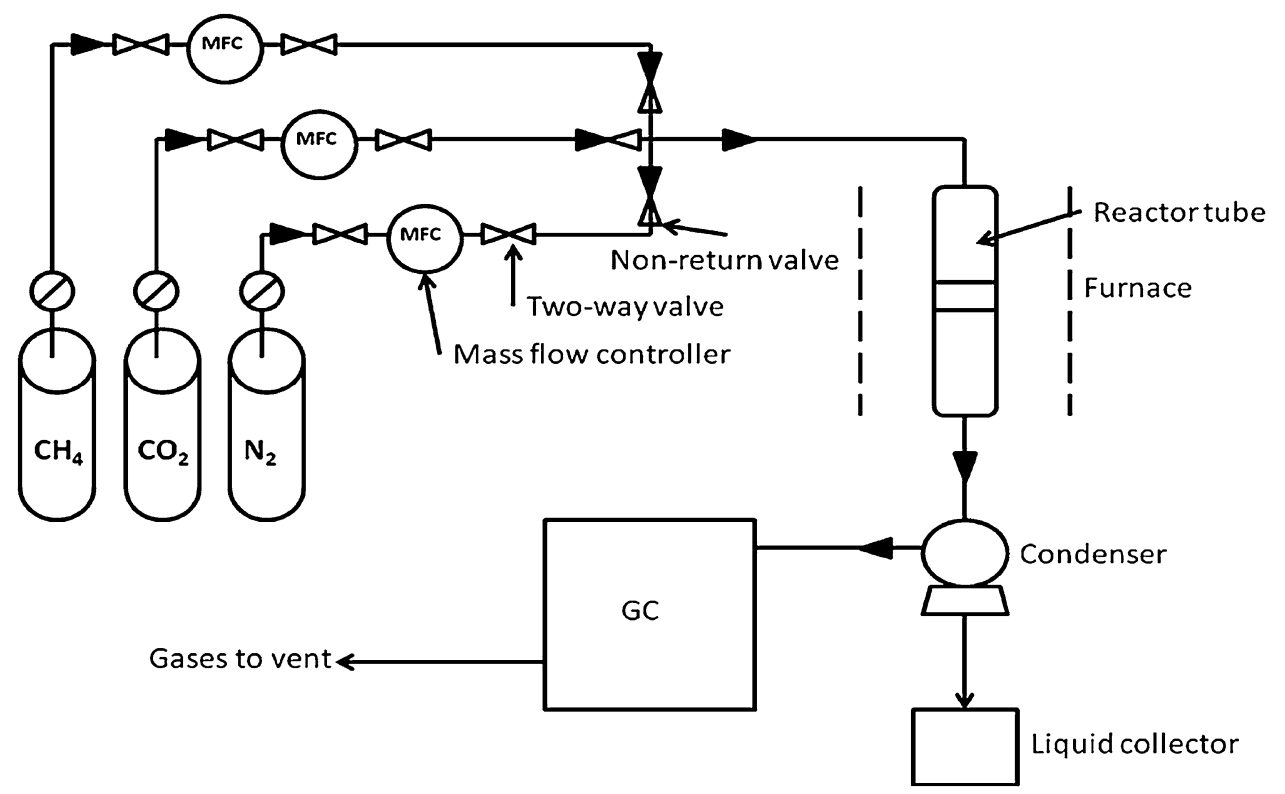

The effect of the reactor tube, carborundum and quartz wool has been accounted for by undertaking a blank experiment. In all instances, this conversion amounted to $<1 \%$ of that demonstrated by the reactor tube loaded with catalysts. All $5 \mathrm{~h}$ data sets presented below represent an average of two experiments with a maximum difference between experiments of $\pm 3 \%$ for $\mathrm{CO}_{2}$ conversion and $\mathrm{CO}$ yield data and $\pm 2 \%$ for $\mathrm{CH}_{4}$ conversion and $\mathrm{H}_{2}$ yield data. All experiments were carbon balanced and found to be close in the range $96-103 \%$.

\section{X-ray diffraction (XRD)}

Measurements were undertaken on a PANalytical X'Pert Pro diffractometer, utilising $\mathrm{CuK}_{\alpha 1}$ radiation; the X-ray tube was operated at $40 \mathrm{kV}$ and $45 \mathrm{~mA}$. The scanning range was $5^{\circ}-85^{\circ}$ in $2 \theta$, with a step size of $0.0020^{\circ}$ and a scan speed of $0.0056^{\circ} \mathrm{s}^{-1}$. Crystallite sizes of the carbidic phase were calculated by employing the Scherer equation and are only presented for comparative purposes.

\section{Thermogravimetric analysis (TGA)}

TGA data were collected on a Perkin Elmer STA6000. 4-7 mg of material was heated in an alumina crucible under a $30 \mathrm{ml} \mathrm{min}^{-1}$ flow of air from 50 to $950{ }^{\circ} \mathrm{C}$ at a ramp rate of $10{ }^{\circ} \mathrm{C} \mathrm{min}^{-1}$.

\section{Nitrogen physisorption (BET method)}

$\mathrm{N}_{2}$ adsorption-desorption isotherms were measured at $-196{ }^{\circ} \mathrm{C}$ using a Micromeritics ASAP2020 specific surface area and porosity analyser. The specific surface area was determined from the $\mathrm{N}_{2}$ adsorption isotherms by application of the BET equation. Prior to analysis, the samples were degassed under vacuum at $150{ }^{\circ} \mathrm{C}$ for $5 \mathrm{~h}$.

Carbon, hydrogen and nitrogen analysis (CHN)

The total weight percentage of carbon, hydrogen and nitrogen was determined for fresh and spent catalysts. This was performed via combustion analysis using an Exeter Analytical CE-440 analyser. Values given within are an average of three measurements and correspond to a maximum difference of $3 \%$.

\section{Results and discussion}

Synthesised catalyst characterisation

Synthesised catalysts were analysed via a variety of techniques to determine composition prior to and after reaction. Table 1 illustrates the carbon contents both prior to and post-reaction; initially it can be observed that all samples contained a significant fraction of carbon, catalysts containing $0,1,5,10$ and $15 \mathrm{wt} \%$ La had $10.5-12.3 \mathrm{wt} \%$ of carbon. In comparison, the bulk $\mathrm{Mo}_{2} \mathrm{C}$ had $\sim 6 \mathrm{wt} \%$ carbon present, hence, this was viewed as a large excess which may have resulted from longer than necessary carburisation times and come about through the methane decomposition reaction as the carbide phase formed. The bulk composition of the bimetallic carbide is predicted as being $\mathrm{Co}_{\mathrm{x}} \mathrm{Mo}_{\mathrm{y}} \mathrm{C}_{\mathrm{z}}$ where $x=2.29, y=3.43$ and $z=1$. Which equates to $8.48 \mathrm{wt} \% \mathrm{Co}, 20.75 \mathrm{wt} \% \mathrm{Mo}, 0.77 \mathrm{wt} \% \mathrm{C} 0.70$ $10.50 \mathrm{wt} \% \mathrm{La}$ and $69.30-59.50 \mathrm{wt} \% \mathrm{Al}_{2} \mathrm{O}_{3}$. It was also 
Table 1 Catalyst characteristics of the La containing supported bimetallic carbide catalysts prior to and post-reaction

\begin{tabular}{llllll}
\hline $\begin{array}{l}\text { Lanthanum } \\
\text { doping } \\
\text { level (wt\%) }\end{array}$ & $\begin{array}{l}\text { Carbon } \\
\text { content } \\
\text { prior to } \\
\text { reaction } \\
(\mathrm{wt} \%)\end{array}$ & $\begin{array}{l}\text { BET } \\
\text { surface } \\
\text { area } \\
\left(\mathrm{m}^{2} \mathrm{~g}^{-1}\right)\end{array}$ & $\begin{array}{l}\text { Carbide } \\
\text { crystallite } \\
\text { size prior } \\
\text { to reaction } \\
(\mathrm{nm})\end{array}$ & $\begin{array}{l}\text { Carbon } \\
\text { content } \\
\text { post- } \\
\text { reaction } \\
(\mathrm{wt} \%)\end{array}$ & $\begin{array}{l}\text { Carbide } \\
\text { crystallite } \\
\text { size post- } \\
\text { reaction } \\
(\mathrm{nm})\end{array}$ \\
\hline 0 & 11.28 & 85 & 12 & 0.73 & 23 \\
1 & 10.64 & 87 & 5 & 0.67 & $20(5 \mathrm{~h})$ \\
& & & & $5.15 \mathrm{~h})$ & $52(100 \mathrm{~h})$ \\
& & & & $0.69 \mathrm{~h})$ & 20 \\
5 & 12.32 & 84 & 11 & 0.65 & 30 \\
10 & 10.50 & 78 & 11 & 0.75 & 20 \\
\hline
\end{tabular}

found that in general, the surface area of the supported catalysts decreased with increased lanthanum content. This may have been an effect caused by the increase in lanthanum content and a decrease in alumina content, resulting in similar levels of coke across supports of reduced surface area and porosity.

XRD patterns of the supports (Fig. 2a) exhibited a small degree of variation in peak intensity which may be attributed to the dilution effect of the lanthanum additive. All catalysts exhibited a number of phases present (Fig. 2b). Unsurprisingly, the most dominant phase was that of carbide. It has been reported in a number of studies that the bimetallic carbide exhibits diffraction peaks shifted to higher diffraction angles compared to $\mathrm{Mo}_{2} \mathrm{C}$ and were similar to those observed for the $\beta$-molybdenum carbide $[35,36]$. The $\gamma$-alumina phase was also observed, in conjunction with amorphous carbon and Co. At the Co:Mo ratio employed (0.67), the carbide structure is known to undergo a degree of phase separation during synthesis which results in a mixture of mono and bimetallic carbides as well as metallic Co [6]. It can also be observed that when small quantities of lanthanum (1 wt $\%)$ were added, the growth of carbidic species was suppressed in comparison to that observed for the undoped sample, as seen from the intensity of the carbide phase peaks (Fig. 2b). As lanthanum addition increased this effect appeared to decrease, where at 10-15 wt $\%$ of lanthanum a significant increase in carbide diffraction peak intensity was observed. This is in line with the observations of Martinez et al. where they observed that catalysts possessing large amounts of lanthanum oxide addition resulted in reduced catalytic activity and stability. From this, they concluded that while lower loading levels of lanthanum oxide resulted in good dispersion and hence an improvement in the active metal dispersion on the catalyst. High loadings resulted in a reversal of this effect, where active metal dispersion was
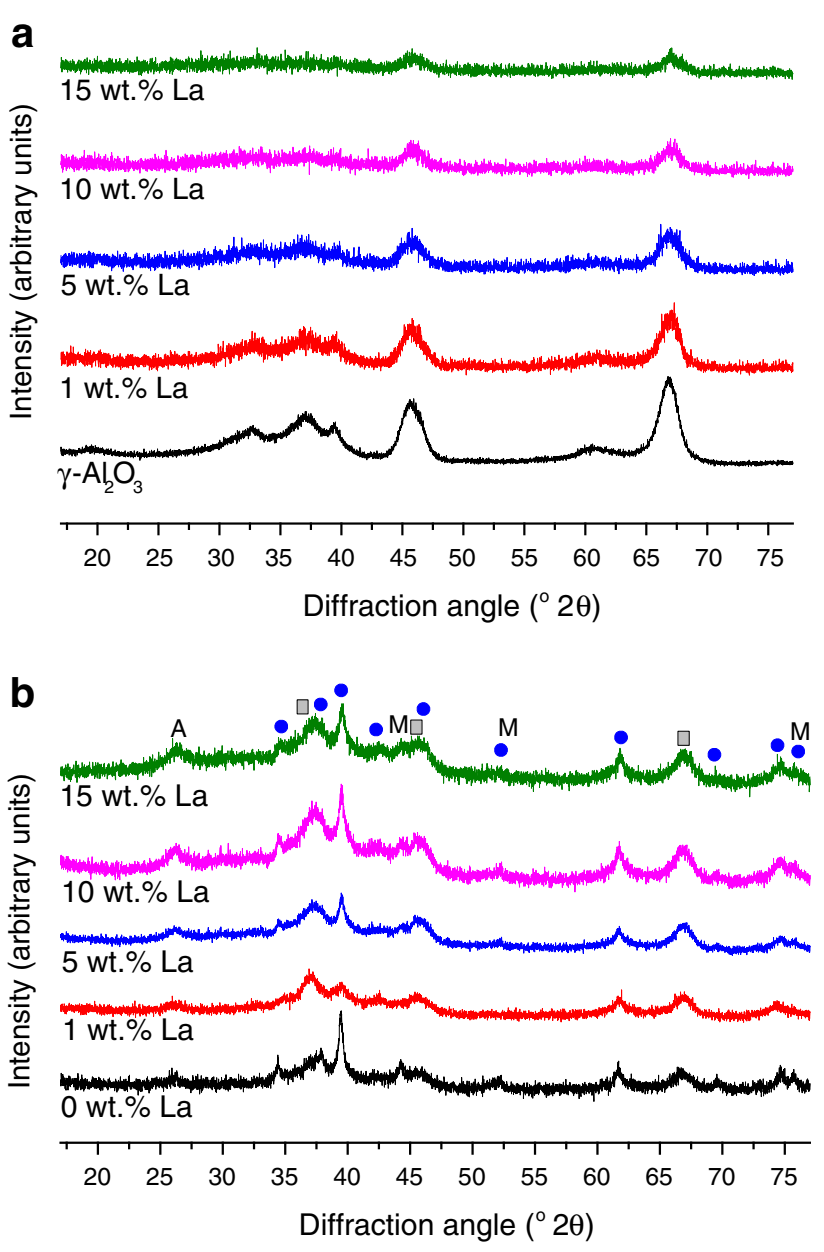

Fig. 2 a XRD patterns of supports containing La additive. b XRD patterns of the La-containing alumina supported bimetallic carbide (40 wt \%) catalysts prior to reaction. A carbon, filled circle carbide, filled square $\gamma$-alumina and $M$ cobalt

found to be worse than that employed on the catalyst with no lanthanum oxide addition [25]. Interestingly, in our study lanthanum oxide diffraction peaks were not observed on any of the supported samples even up to $15 \mathrm{wt} \%$ of lanthanum, which suggested that lanthanum derived species were highly dispersed on the support. This observation is in good agreement with work previously undertaken by [13] who reported that a $\mathrm{La}: \mathrm{Al}$ ratio of $0.15(\sim 9.3 \mathrm{wt} \%$ of La) resulted in high dispersion of the $\mathrm{La}$ phase as $\mathrm{La}^{3+}$. These dispersion effects were observed to be present at higher La:Al ratios $(0.25-0.50)$, however, it was found that excess lanthanum species may have become partially incorporated in the alumina framework giving rise to species of the type $\mathrm{LaAlO}_{3}$ resulting in reduced support surface area.

TGA was used to examine the reaction of the supported bimetallic carbides under an oxidising atmosphere. It can be seen in Fig. 3 that all catalysts exhibited a series of mass changes over the range $200-650{ }^{\circ} \mathrm{C}$. Monometallic carbides 


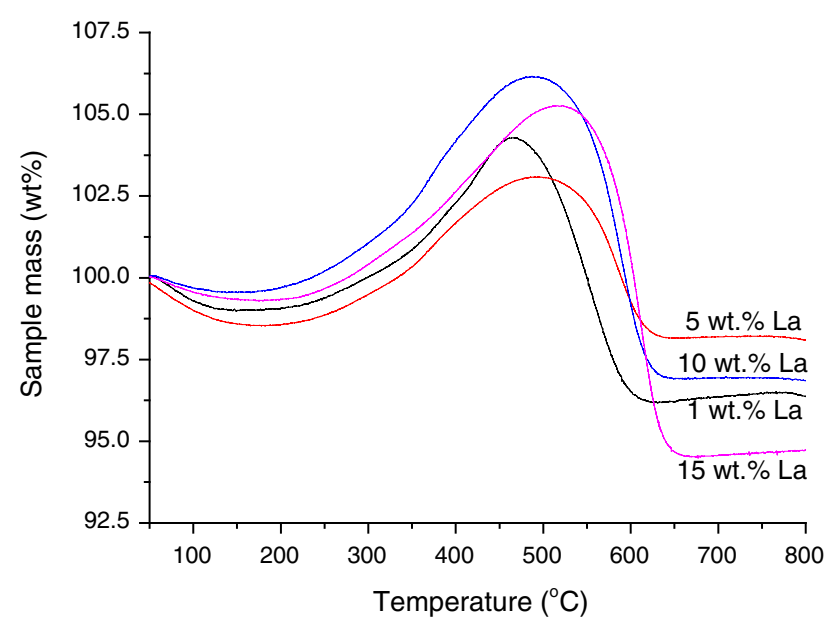

Fig. 3 TGA of the La-containing alumina supported bimetallic carbide catalysts prior to reaction

are known to be highly reactive in the presence of oxygen and readily undergo a transformation to their respective oxide phases [2]. However, in this instance, this does not appear to be a rapid transformation for any of the catalysts. In all instances, these events occur over a prolonged period from $200{ }^{\circ} \mathrm{C}$ until a maximum mass increase was observed between $475{ }^{\circ} \mathrm{C}(1 \mathrm{wt} \% \mathrm{La})$ and $550{ }^{\circ} \mathrm{C}(15 \mathrm{wt} \%$ la). Presumably, this is due to the formation of a protective oxide overlayer on the carbidic species, inhibiting rapid oxidation [30]. Additionally cobalt, the second metal employed in these systems, is known to undergo a convoluted oxidation process over a wide temperature range, which may also significantly contribute to the elongation of the oxidative events [34]. After this process, a significant mass loss is observed which coincides with the removal of carbonaceous species deposited on the catalyst during the carburisation process, these temperatures are similar to those observed by Jiang et al. [16] over spent nickel catalyst supported on aerogels. Interestingly, the increased oxidation temperatures coincided with increased lanthanum content. This could suggest that increased La enhanced the carbidic and metallic species oxidative resistance. This effect appears to have affected the combustion process associated with deposited carbon species. It may be inferred that the combustion of the deposited carbon is a catalytic process and that the observed differences in temperature are associated with the formation of active metal oxide species [24].

\section{Catalytic tests}

To further examine the effects that lanthanum addition has on the bimetallic carbide, reactions were undertaken employing an excess of carbon dioxide at $850{ }^{\circ} \mathrm{C}$ for a duration of $300 \mathrm{~min}$. It can be observed in Fig. 4a that all lanthanum dispersed catalysts exhibited a methane conversion of above $97.5 \%$ which was well in line with calculated equilibrium values ( $>99 \%$ ) [3]. However, for the undoped sample, a lower conversion indicates that lanthanum may have acted as a promoter for methane decomposition. It was demonstrated by Jiang et al. [17] that the addition of lanthanum oxide to nickel-containing catalysts resulted in enhanced methane conversion, especially at higher temperatures. It was apparent that after $300 \mathrm{~min}$ very little change was observed for the methane conversion. This suggested that conversion of methane occurred readily over all materials regardless of carbon dioxide conversion. To further verify whether this was due to dry methane reforming, methane decomposition or a combination of both, the carbon dioxide conversion was analysed to establish the presence of such potential side reactions.

The samples containing 1 and $10 \mathrm{wt} \%$ of lanthanum exhibited similar $\mathrm{CO}_{2}$ conversions comparable to those observed for the undoped sample (Fig. 4b). Interestingly, this runs in parallel to the carbon content of each catalyst and more importantly to amount of carbon remaining postreaction (Table 1). We may assume that due to the carbon balances observed, the surface carbon prior to reaction is removed before sampling of the product gases occurs at $30 \mathrm{~min}$. Additionally, it is proposed that this occurs in part due to the larger amount of $\mathrm{CO}_{2}$ employed in this process in comparison to methane. The catalyst with $1 \mathrm{wt} \% \mathrm{La}$ exhibited a higher degree of stability during the $5 \mathrm{~h}$ reaction, whereas the undoped and the $10 \mathrm{wt} \% \mathrm{La}$ catalysts exhibited a small decrease in conversion during the 300 min reactions. Both the 5 and $15 \mathrm{wt} \%$ La exhibited very similar initial carbon dioxide conversion values at $\sim 94 \%$, however, the $15 \mathrm{wt} \%$ La deactivated during the course of the reaction to $\sim 89 \%$. A slower rate of deactivation was observed for the $5 \mathrm{wt} \%$ La catalyst which displayed only a decrease of $3 \%$.

The yields generated by each catalyst were analysed to assess the effects that lanthanum addition had on side reactions commonly found in dry methane reforming, most notably hydrogen-consuming reactions, for example reverse water-gas shift (RWGS). It can be observed in Fig. $4 \mathrm{c}, \mathrm{d}$ that the sample containing $1 \mathrm{wt} \%$ La exhibited the highest yield of hydrogen $(\sim 96 \%)$ and carbon monoxide $(\sim 82 \%)$. While higher loadings show an effect which favours significant side reactions that result in reduced yields of hydrogen and carbon monoxide. The final assessment of the catalysts was the analysis of the product ratios (Fig. 4e), which in a near ideal scenario (Eq. 2) would be close to $1: 1$. However, this is normally difficult to achieve due to the ongoing side processes, for example $\mathrm{MCr}$ and RWGS. The materials that resulted in ratios closest to the optimal were the 0 and $1 \mathrm{wt} \%$ La-doped catalysts, which produced a fairly stable ratio of approximately $0.98-1.02$ (based upon duplicate data sets). All of 

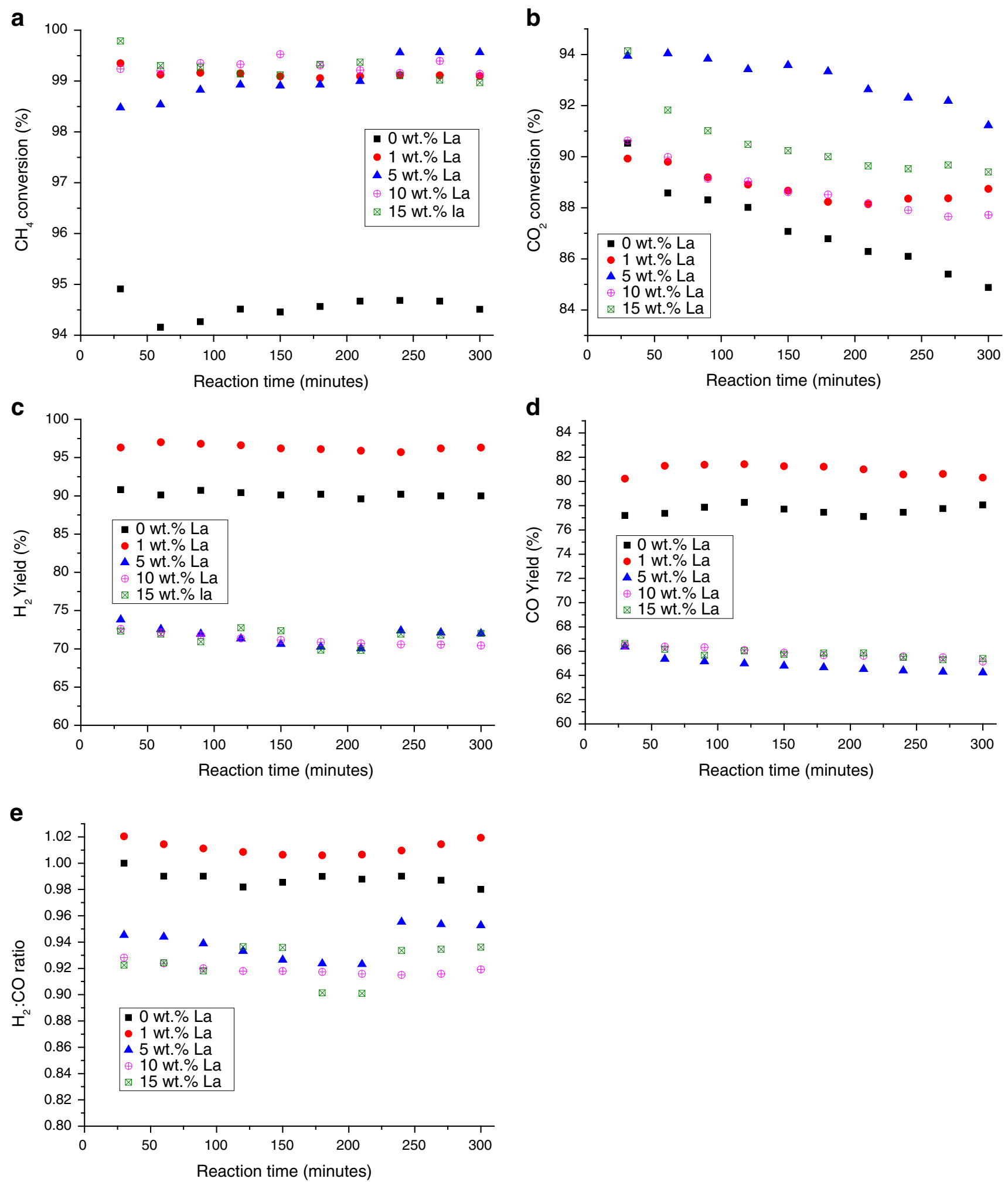

Fig. 4 Dry methane reforming reaction data for La containing supported bimetallic carbides. a methane conversion, b carbon dioxide conversion, c hydrogen yield, $\mathbf{d}$ carbon monoxide yield and $\mathbf{e} \mathrm{H}_{2}$ : $\mathrm{CO}$ ratio

the other $\mathrm{H}_{2} / \mathrm{CO}$ ratios were in the range of $0.90-0.96$. It is evident at higher loadings of lanthanum that carbon monoxide is the favoured product.
These observed differences in reactivity may stem from the presence of new diffraction peaks observed in postreaction XRD patterns of spent catalysts (Fig. 5). It was 


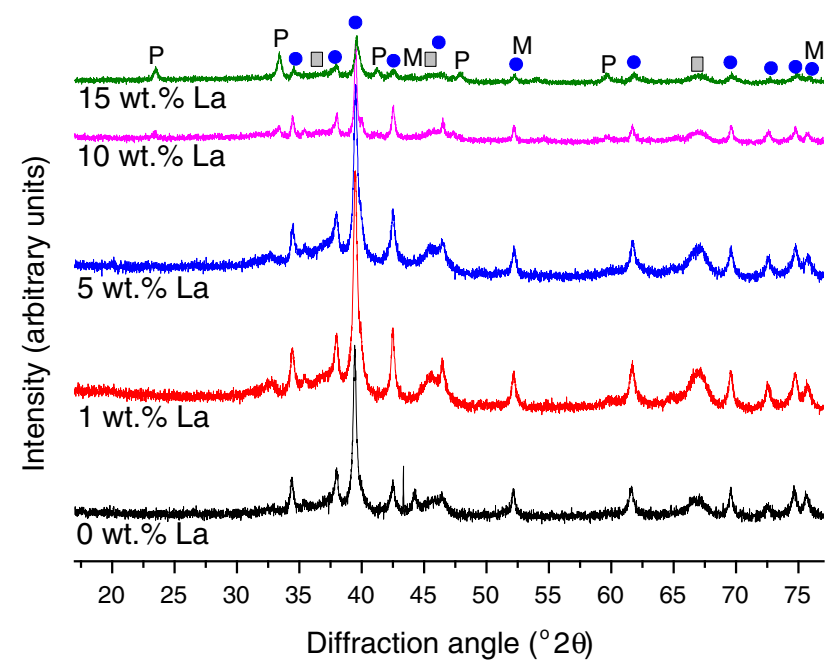

Fig. 5 Post-reaction XRD patterns of the La-containing alumina supported bimetallic carbide catalysts. $P \mathrm{LaCoO}_{3}$, filled circle carbide, filled square $\gamma$-alumina and $M=$ cobalt

found that a new phase was formed during the reaction and matched the perovskite $\mathrm{LaCoO}_{3}$. Recently, Chawla et al. [5] demonstrated that lanthanum cobaltite possesses a degree of catalytic activity towards dry methane reforming, they also found that the working catalyst exhibited a high degree of RWGS activity as indicated by a $\mathrm{H}_{2}$ : $\mathrm{CO}$ ratio lower than 1 . This may partially explain why all loading levels above $1 \mathrm{wt} \%$ La exhibit a high degree of RWGS activity.

Post-reaction characterisation

Catalysts were cooled to room temperature under flowing nitrogen and once cooled, allowed to passivate in air prior to removal from the reactor. Elemental analysis (Table 1) was conducted on the post-reaction catalysts and in all instances, the carbon content of the material had decreased significantly, indicating removal of the excess amorphous carbon via direct reaction with carbon dioxide (reverse Boudouard $(\mathrm{RB})$ reaction $\Delta \mathrm{H}_{298}^{\circ}=172 \mathrm{~kJ} \mathrm{~mol}^{-1}$ ). Similar levels of residual carbon were observed over the spent catalysts, which in conjunction with post-reaction XRD patterns (Fig. 5) indicated the presence of carbide phases in post-reaction catalysts. It should also be noted that although not presented in Table 1, all post-reaction samples displayed a very small quantity of hydrogen (0.03 wt\%), which may be in the form of adsorbed hydrocarbons [31]. XRD patterns also indicated that the carbide phase peak intensity had increased substantially on catalysts that contained lower lanthanum content. Previously, lanthanum has been demonstrated to act as a dispersion agent on alumina providing improved dispersion of supported phases [13]. Hence, loss of lanthanum through

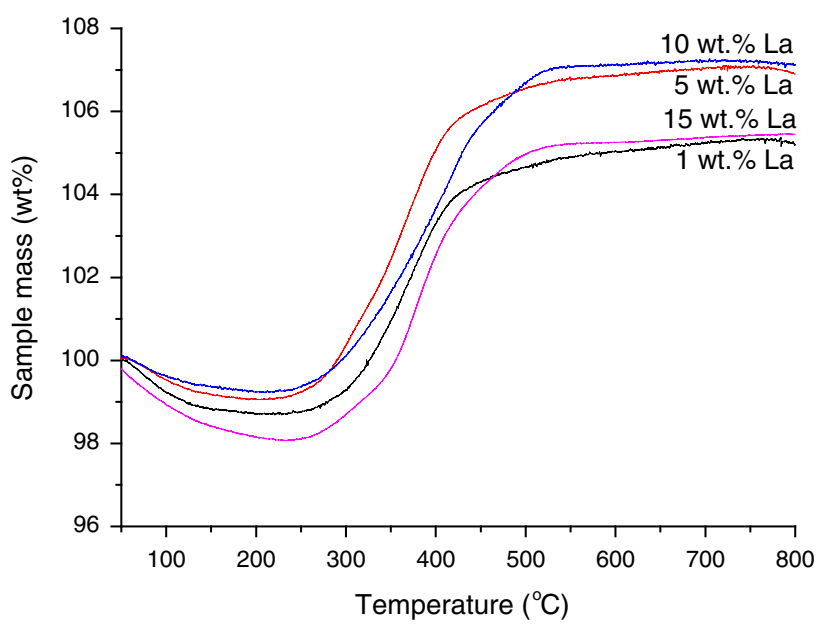

Fig. 6 Post-reaction TGA of the La-containing alumina supported bimetallic carbide catalysts

the formation of a perovskite phase [15] would reduce the amount of lanthanum and alter this dispersion effect which may have resulted in the significant sintering during reaction (Table 1).

TGA thermographs (Fig. 6) exhibit a number of phenomena in post-reaction catalysts. Initially, a small mass loss was observed at a similar level to that found prior to reaction, suggesting that this may be associated with either water loss and/or buoyancy as a result of the up flow system. After this initial loss, an increase in mass was observed indicating the presence of carbidic and metallic species being present over the spent catalyst which oxidised during TGA experiments. In all instances, these mass increases were found to begin within the range $200-225{ }^{\circ} \mathrm{C}$ which was similar to those observed prior to reaction. At maximum oxidation, it became apparent that there were differences in the degree of oxidation of the materials. Additionally, the remaining residual carbon observed via elemental analysis did not appear to be associated with graphitic coke. Based upon the findings from XRD, the carbidic phases still appear to be the major components on the support. This is further verified by the theoretical carbon content of the carbides. Bulk bimetallic carbides synthesised by Xiao et al. [37] exhibited a carbon content of $\sim 2.56 \mathrm{wt} \%$ at the same ratio employed within this study. The approximate loading level of the supported carbides in this instance is $30 \mathrm{wt} \%$. Based upon this, the theoretical carbon content of the catalyst should be $0.77 \mathrm{wt} \%$. Hence, it is observed that post-reaction carbon contents of all materials are similar to those expected theoretically.

100 hour catalytic test

Based upon the observations made during the $5 \mathrm{~h}$ test reactions (low activity towards side reactions), the $1 \mathrm{wt} \%$ 

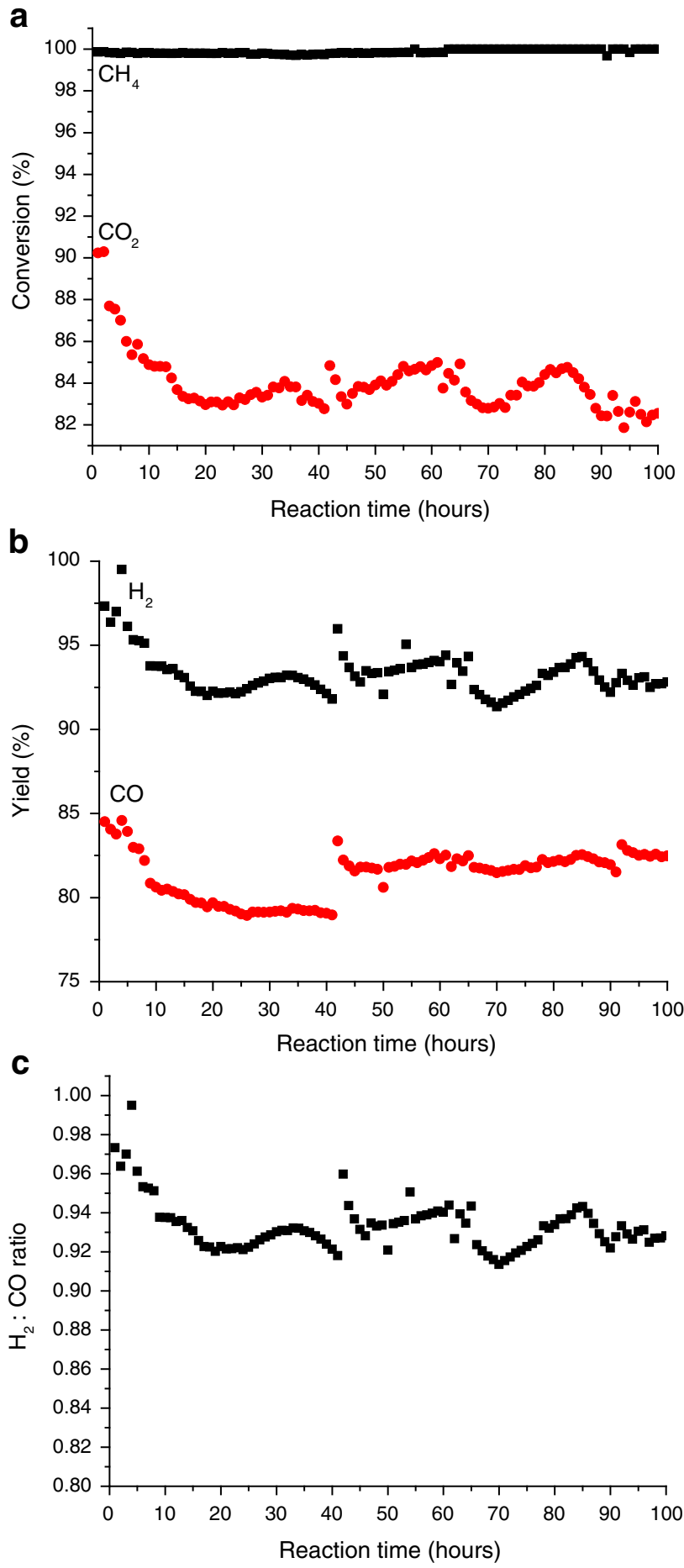

Fig. 7100 hour reaction data for the $1 \mathrm{wt} \%$ La-containing alumina supported bimetallic carbide catalyst. a methane and carbon dioxide conversion, b hydrogen and carbon monoxide yields and $\mathbf{c}_{2}: \mathrm{CO}$ ratio

La doped supported bimetallic carbide catalyst was tested in an extended time on stream study for $100 \mathrm{~h}$. It was found that during the course of the reaction, a drop in carbon dioxide conversion was observed, however, after $\sim 12 \mathrm{~h}$, this appeared to stabilise at $\sim 84 \%$ with minor fluctuations of $\pm 1 \%$ (Fig. 7a). In contrast to this, the methane conversion ( $99 \%$ ) remained unchanged for $100 \mathrm{~h}$. Analysis of the yields (Fig. $7 b$ ) revealed a gradual decline in the product quantity. The yield of carbon monoxide was found to decrease from $\sim 85$ to $82 \%$ during the course of the reaction. This trend was mirrored by the hydrogen yield where it decreased from $\sim 99$ to $92 \%$.

During the reaction, the carbon dioxide feed failed at $41 \mathrm{~h}$, subsequently all feeds except nitrogen were switched immediately to prevent carbon deposition occurring and the reactor was cooled to room temperature. The reactor was brought back online in the same manner as initial startup and measurements were resumed. It can be observed that at $\sim 42 \mathrm{~h}$, an increase in yields (Fig. $7 \mathrm{~b}$ ) was apparent, suggesting that the catalyst had been partially reactivated through the reheating cycle under the inert gas. However, soon after this, the catalyst re-established similar conversion and yield levels to those observed prior to reactor shutdown. A small increase in the carbon monoxide yield may be attributable to carbon laid down on the catalyst as lanthanum species (which are known to help prevent carbon deposition [33]) were converted to the perovskite. Presumably with no corresponding increase in $\mathrm{CO}_{2}$ conversion this can be associated with the $\mathrm{RB}$ reaction. The product ratio (Fig. 7c) exhibited a general decline from 0.99 to 0.96 across the course of the reaction, indicating an increase in the carbon monoxide and/or a subsequent decrease in the hydrogen content of the produced syngas.

\section{Post-reaction characterisation}

In the previous section, three major effects were observed during the reaction, these being; decreasing $\mathrm{CO}_{2}$ conversion, decreasing $\mathrm{H}_{2}$ yield and an increasing $\mathrm{CO}$ yield during the latter stages of the reaction. To explain these observations, the spent catalyst was characterised after reaction and compared to the pre-reaction and the spent catalyst obtained post $5 \mathrm{~h}$. After $100 \mathrm{~h}$, the catalyst exhibited a significant degree of sintering as evidenced by the change in the calculated crystallite sizes (Fig. 8; Table 1). Very little change in the cobalt metal and perovskite diffraction peaks was observed at $100 \mathrm{~h}$ time on stream in comparison to that observed for $5 \mathrm{~h}$, suggesting that these changes occurred early on in the reaction. It can be observed in Fig. 9 that the $100 \mathrm{~h}$ time on stream catalyst exhibited an almost identical TGA thermograph to the $5 \mathrm{~h}$ time on stream catalyst after $600{ }^{\circ} \mathrm{C}$. Prior to this, two additional features are observed in the form of an inflection point at $375{ }^{\circ} \mathrm{C}$ which may be associated with delayed oxidation of sintered particles (evidenced previously via $\mathrm{XRD)}$ in conjunction with the loss of amorphous carbon.

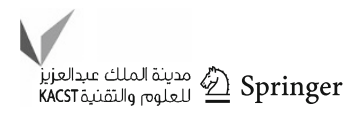




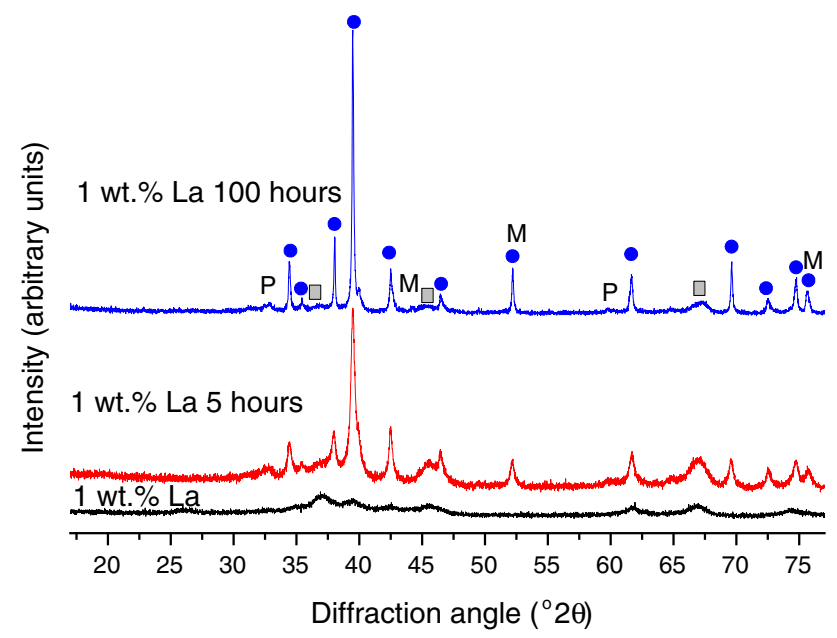

Fig. 8 XRD patterns of the $1 \mathrm{wt} \%$ La-containing alumina supported bimetallic carbide catalysts prior to and post-reaction at 5 and $100 \mathrm{~h}$ TOS. $P=\mathrm{LaCoO}_{3}$, filled circle carbide, filled square $\gamma$-alumina and $M=$ cobalt

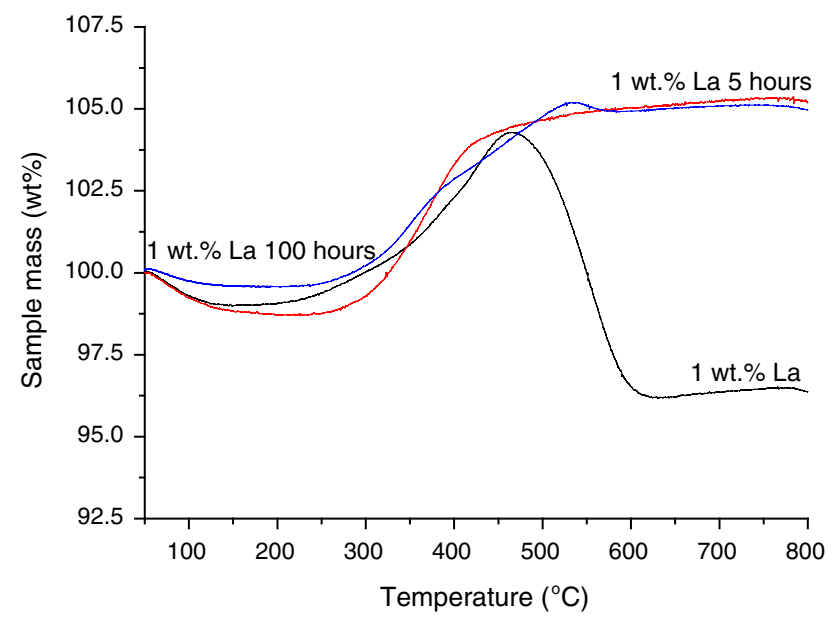

Fig. 9 TGA of the 1 wt\% La-containing alumina supported bimetallic carbide catalysts prior to and post-reaction at 5 and $100 \mathrm{~h}$ time on stream

The second feature is also apparent at $\sim 525{ }^{\circ} \mathrm{C}$ associated with subsequent oxidation of graphitic carbon [16].

\section{Summary}

Addition of lanthanum exhibited a number of beneficial effects at low loading levels, such as reduced carbide crystallite size and improved methane conversion in conjunction with improved catalyst stability. Higher loading levels resulted in similar carbide crystallite sizes as those observed over the catalyst containing no lanthanum addition. This increase in lanthanum content had a negative effect upon the reaction resulting in significant enhancement of side reactions in conjunction with increased carbon dioxide conversion. As an interesting aside during these reactions, it was apparent that a new phase was formed $\left(\mathrm{LaCoO}_{3}\right)$, which previously has never been successfully synthesised directly over $\gamma$-alumina. It has been documented that such phases possess activity for both dry methane reforming as well as reverse water gas shift, perhaps indicating, why larger lanthanum loadings had such an adverse effect upon the reaction.

At longer reaction times, the $1 \mathrm{wt} \%$ catalyst exhibited an initial loss of carbon dioxide conversion and hydrogen and carbon monoxide yields. Indicating that after $5 \mathrm{~h}$, a significant change in the material occurred, causing a more pronounced change in the reaction than that observed previously during the $5 \mathrm{~h}$ runs. However, after this period the catalyst exhibited significant stability, with only a small increase occurring in the generation of carbon monoxide and subsequently a small $(3 \%)$ reduction in the $\mathrm{H}_{2}: \mathrm{CO}$ ratio during the $100 \mathrm{~h}$ examined. Based upon the observations made post-reaction, it appears that the loss of activity may be related to sintering of the active phase. The change observed in the carbon monoxide yield is believed to a shift in side reactions from reverse water gas shift to the reverse Boudouard reaction, which would account for this enhancement effect.

\section{Conclusions}

Increased addition of lanthanum resulted in increased particle size of the carbide phase over the alumina support. This also occurred in conjunction with an increase in $\mathrm{CO}_{2}$ adsorption over the catalyst with increasing lanthanum content. Several changes were observed in the catalytic activity of the catalysts. Upon addition of lanthanum an increase of 4-5\% methane conversion was observed, indicating the presence of lanthanum, enhanced reactions associated with methane. Further to this, materials that contained significantly more carbon (3,5 and $15 \mathrm{wt} \%$ ) possessed a higher conversion of carbon dioxide, however, only the materials containing 0,1 and $3 \mathrm{wt} \%$ exhibited stability over the $5 \mathrm{~h}$ reaction. Catalysts containing 3-15 wt\% lanthanum possessed low product yields due to a number of ongoing side reactions such as the reverse water-gas shift reaction. However, the 0 and $1 \mathrm{wt} \%$ catalysts exhibited high product yields indicating minimised side reactions. Post-reaction data suggested that these differences in activity may be attributed to the formation of the $\mathrm{LaCoO}_{3}$ perovskite structure for samples containing higher lanthanum loading levels. For materials containing $1 \mathrm{wt} \% \mathrm{La}$, a significant sintering effect was observed, which during the course of the short time on stream study had very little effect on the catalyst stability. Longer reaction times for the $1 \mathrm{wt} \%$ La-containing catalyst 
exhibited a decrease in conversion up to $12 \mathrm{~h}$ time on stream, which may have been caused by significant sintering of the active carbide phase and hence a reduction in the effective catalyst surface area. However, after $12 \mathrm{~h}$, the catalyst remained relatively stable exhibiting a small increase in carbon monoxide yield, which was as a result of carbon deposition on the catalyst due to the loss of the lanthanum phase through the generation of the $\mathrm{LaCoO}_{3}$ phase.

Acknowledgments The authors would like to thank KACST for their kind generosity in funding the KOPRC lab, a post-doctoral research position and supporting the carbon dioxide activation project at the University of Oxford. We would like to thank Professor Xiaoqin Qin from Shanxi University for kindly undertaking gas adsorption measurements. We would also like to acknowledge Dr Justin Hargreaves from the University of Glasgow for his useful advice and fruitful discussions on binary and ternary interstitial compounds.

Open Access This article is distributed under the terms of the Creative Commons Attribution License which permits any use, distribution, and reproduction in any medium, provided the original author(s) and the source are credited.

\section{References}

1. Al-Megren H, Gonzalez-Cortes S, Xiao T, Green M (2007) A comparative study of the catalytic performance of $\mathrm{Co}-\mathrm{Mo}$ and $\mathrm{Co}(\mathrm{Ni})-\mathrm{W}$ carbide catalysts in the hydrodenitrogenation (HDN) reaction of pyridine. Appl Catal A 329:36

2. Brungs AJ, York APE, Claridge JB, Marquez-Alvarez C, Green MLH (2000) Dry reforming of methane to synthesis gas over supported molybdenum carbide catalysts. Catal Lett 70:117

3. Budiman AW, Song S-H, Chang T-S, Shin C-H, Choi M-J (2012) Dry reforming of methane over cobalt catalysts: a literature review of catalyst development. Catal Surv Asia 16:183

4. Burghgraef H, Jansen APJ, van Santen RA (1995) Methane activation and dehydrogenation on nickel and cobalt: a computational study. Surf Sci 324:345

5. Chawla S, George M, Patel F, Patel S (2013) Production of synthesis gas by carbon dioxide reforming of methane over nickel based perovskite catalysts. Procedia Eng 51:461

6. Cheng J, Huang W (2010) Effect of cobalt (nickel) content on the catalytic performance of molybdenum carbides in dry-methane reforming. Fuel Process Technol 91:185

7. Christofoletti T, Assaf JM, Assaf EM (2005) Methane reforming on supported and non-supported molybdenum carbides. Chem Eng J 106(2):97

8. Darujati ARS, Thomson WJ (2005) Stability of supported and promoted-molybdenum carbide catalysts in dry-methane reforming. Appl Catal A 296(2):139

9. Darujati ARS, Thomson WJ (2006) Kinetic study of a ceriapromoted $\mathrm{Mo} 2 \mathrm{C} / \gamma-\mathrm{Al} 2 \mathrm{O} 3$ catalyst in dry-methane reforming. Chem Eng Sci 61(13):4309

10. Diaz B, Sawhill SJ, Bale DH, Main R, Phillips DC, Korlann S, Self R, Bussel ME (2003) Hydrodesulfurization over supported monometallic, bimetallic and promoted carbide and nitride catalysts. Catal Today 86:191

11. Er-rbib H, Bouallou C, Werkoff F (2012) Dry reforming of methane-review of feasibility studies. Chem Eng Trans 29:163
12. Francisco MSP, Mastelaro VR (2002) Inhibition of the anataserutile phase transformation with addition of $\mathrm{CeO}_{2}$ to $\mathrm{CuO}-\mathrm{TiO}_{2}$ system: raman spectroscopy, $\mathrm{X}$-ray diffraction and textural studies. Chem Mater 14:2514

13. Haack L, de Vries J, Otto K, Chattha M (1992) Characterization of lanthanum modified $\gamma$-alumina by X-ray photoelectron spectroscopy and carbon dioxide adsorption. Appl Catal A 82:199

14. Huang T, Huang W, Huang J, Ji P (1868) Methane reforming reaction with carbon dioxide over SBA-15 supported Ni-M0 bimetallic catalysts. Fuel Process Technol 2011:92

15. Ito T, Zhang Q, Saito F (2004) Synthesis of perovskite-type lanthanum cobalt oxide nanoparticles by means of mechanochemical treatment. Powder Technol 143-144:170

16. Jiang Z, Liao X, Zhao Y (2013) Comparative study of the dry reforming of methane on fluidised aerogel and xerogel Ni/Al $\mathrm{O}_{3}$ catalysts. Appl Petrochem Res 3:91

17. Jiang P, Shang Y, Cheng T, Bi Y, Shi K, Wei S, Xu G, Zhen K (2003) Methane decomposition over $\mathrm{Ni}$ alpha- $\mathrm{Al}_{2} \mathrm{O}_{3}$ promoted by $\mathrm{La}_{2} \mathrm{O}_{3}$ and $\mathrm{CeO}_{2}$. J Nat Gas Chem 12:183

18. Kim S, Lee S, Song K (2007) Performance of Ni catalyst supported on La-hexaaluminate in $\mathrm{CO}_{2}$ reforming of $\mathrm{CH}_{4}$. Korean $\mathrm{J}$ Chem Eng 24(3):477

19. Korlann S, Diaz B, Bussell ME (2002) Synthesis of bulk and alumina supported bimetallic carbide and nitride catalysts. Chem Mater 14:4049

20. Kumar R, Wu-Cheng C, Sutovich KJ, Ziebarth MS, Yuying S (2014) High matrix surface area catalytic cracking catalyst stabilized with magnesium and silica, Patent US 2014/0021098

21. LaMont DC, Thomson WJ (2004) The influence of mass transfer conditions on the stability of molybdenum carbide for dry methane reforming. Appl Catal A 274(1-2):173

22. Levy RB, Boudouard M (1973) Platinum-like behaviour of tungsten carbide in surface catalysis. Science 181:547

23. Liang C, Ma W, Feng Z, Li C (1833) Activated carbon supported bimetallic CoMo carbides synthesized by carbothermal hydrogen reduction. Carbon 2003:41

24. Lojewska J, Kolodziej A, Zak J (2007) Promoted cobalt oxide catalyst on the metallic structured reactor filling for VOC combustion as an alternative to noble metal catalysts. Pol J Chem Technol 1:15

25. Martinez R, Romero E, Garcia L, Bilbao R (2003) The effect of lanthanum on $\mathrm{Ni}-\mathrm{Al}$ catalyst for catalytic steam gasification of pine sawdust. Fuel Process Technol 85:201

26. Pritchard ML, McCauley RL, Gallaher BN, Thomson WJ (2004) The effect of sulfur and oxygen on the catalytic activity of molybdenum carbide during dry methane reforming. Appl Catal A 275(1-2):213

27. Puello-Polo E, Gutierrez-Alejandre A, Gonzalez G, Brito JL (2010) Relationship between sulfidation and HDS catalytic activity of activated carbon supported $\mathrm{Mo}, \mathrm{Fe}-\mathrm{Mo}, \mathrm{Co}-\mathrm{Mo}$ and $\mathrm{Ni}-\mathrm{Mo}$ carbides. Catal Lett 135:212

28. Reuters (2013) Israel's new motor fuels strategy leans on gas, www.trust.org/item/20131224115423-31f0m Accessed 21 Feb 2014

29. Sanchez-Castillo MA, Madon RJ, Dumesic JA (2005) Role of rare earth cations in Y zeolite for hydrocarbon cracking. J Phys Chem B 109:2164

30. Schwartz V, Oyama ST, Chen JG (2000) Supported bimetallic Nb-Mo carbide: synthesis, characterization and reactivity. J Phys Chem B 104:8800

31. Silverwood IP, Hamilton NG, Laycock CJ, Staniforth JZ, Ormerod RM, Frost CD, Parker SF, Lennon D (2010) Quantification of surface species present on a nickel/alumina methane reforming catalyst. Phys Chem Chem Phys 12:3102

32. Song $\mathrm{C}$ (2001) Tri-reforming: a new process for reducing $\mathrm{CO}_{2}$ emissions. Chem Innov 31:21

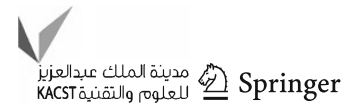


33. Sutthiumporn K, Maneerung T, Kathiraser Y, Kawi S (2012) $\mathrm{CO} 2$ dry-reforming of methane over $\mathrm{La} 0.8 \mathrm{Sr} 0.2 \mathrm{Ni} 0.8 \mathrm{M} 0.2 \mathrm{O} 3$ perovskite $(\mathrm{M}=\mathrm{Bi} \mathrm{Co}, \mathrm{Cr}, \mathrm{Cu}, \mathrm{Fe})$ : roles of lattice oxygen on $\mathrm{C}-\mathrm{H}$ activation and carbon suppression. Int $\mathrm{J}$ Hydrogen Energy 37:11195

34. Tompkins HG, Augis JA (1981) The oxidation of cobalt in air from room temperature to $467{ }^{\circ} \mathrm{C}$. Oxid Met 16:355

35. Wang XH, Zhang MH, Li W, Tao KY (2008) Synthesis and characterization of cobalt-molybdenum bimetallic carbide catalysts. Catal Today 131:111
36. Xiao T, Wang HT, York APE, Green MLH (2002) Effect of sulfur on the performance of molybdenum carbide catalysts for the partial oxidation of methane to synthesis gas. Catal Lett 83(3-4): 241

37. Xiao T, York APE, Al-Megren H, Williams CV, Wang HT, Green MLH (2001) Preparation and characterisation of bimetallic cobalt and molybdenum carbides. J Catal 202(1):100 